\title{
Acute glycaemic effects of co-trimoxazole at prophylactic dose in healthy adults
}

\author{
Bernold Kenteu', Jean Jacques N. Noubiap², Martine Claude Etoa ${ }^{1,3}$, Marcel Azabji-Kenfack ${ }^{4}$, \\ Mesmin Dehayem ${ }^{3}$ and Eugene Sobngwi $i^{1,3,5,6^{*}}$
}

\begin{abstract}
Background: Cases of severe hypoglycaemia were reported in HIV/AIDS patients receiving high dose of the sulfonylurea co-trimoxazole for opportunistic infections. Whether co-trimoxazole at prophylactic dose would induce similar side effects is unknown. We aimed to investigate the acute effects of co-trimoxazole at prophylactic dose on glucose metabolism in healthy adults.

Methods: We enrolled 20 healthy volunteers (15 males and 5 females) aged 23.0 (SD 2.0) years, with mean BMI of $22.3(\mathrm{SD} 3.6) \mathrm{Kg} / \mathrm{m}^{2}$ with normal glucose tolerance, hepatic and renal function. We performed a $75-\mathrm{g}$ oral glucose tolerance test (OGTT) with and without concomitant oral co-trimoxazole administered 60 min before the test. Blood glucose response was measured using a capillary test at baseline and at 30,60, 90, 120 and 180 min following oral glucose load on the two occasions. C-peptide response was also measured. Absolute values of blood glucose and C-peptide with and without co-trimoxazole were compared using the Wilcoxon test.

Results: During the OGTT without co-trimoxazole (control) vs. the OGTT with co-trimoxazole (test), the glycaemia varied from $4.83(\mathrm{SD} 0.39) \mathrm{mmol} / \mathrm{l}$ vs. $4.72(\mathrm{SD} 0.28) \mathrm{mmol} / \mathrm{l}$ at T0 $(P=0.667)$, to $8.00(\mathrm{SD} 1.11) \mathrm{mmol} / \mathrm{l} \mathrm{vs} .7 .44$ (SD 0.78) $\mathrm{mmol} / \mathrm{l}$ at T30 $(P=0.048), 8.00(\mathrm{SD} 1.17) \mathrm{mmol} / \mathrm{l} \mathrm{vs} .7 .67$ (SD 1.00) $\mathrm{mmol} / \mathrm{l}$ at T60 $(P=0.121), 7.33$ (SD 0.94) $\mathrm{mmol} / \mathrm{l}$ vs. 7.11 (SD 0.83) $\mathrm{mmol} / \mathrm{l}$ at T90 ( $P=0.205), 6.78$ (SD 1.00) $\mathrm{mmol} / \mathrm{l}$ vs. $6.67(\mathrm{SD} 1.00) \mathrm{mmol} / \mathrm{l}$ at T120 $(P=0.351)$ and 4.72 (SD 1.39) $\mathrm{mmol} / \mathrm{l}$ vs. 4.72 (SD 1.56) $\mathrm{mmol} / \mathrm{l}$ at T180 ( $P=0.747)$. The ratio of area under the glycaemia curve during the control and test investigation was $96.7 \%$, thus a 3.3 decreased glycaemic response $(p=0.062)$. A decrease of glycaemia by more than $10 \%$ occurred in $6 / 20$ participants at T30, 7/20 participants at T60 and 1/20 participant at T30 and T60. None of the volunteers experienced co-trimoxazole-induced hypoglycaemia. At the same time, the C-peptide response during the control vs. the test investigation varied from 278.1 (SD 57.5) pmol// vs. 242.8 (SD 42.5) $\mathrm{pmol} / \mathrm{l}$ at T0 $(P=0.138)$, to 1845.6 (SD 423.6) pmol// vs. 2340.6 (SD 701.3) pmol// at T60 ( $P=0.345)$ and 1049.8 (SD 503.1) $\mathrm{pmol} / \mathrm{l}$ vs. $1041.63(\mathrm{SD} 824.21) \mathrm{pmol} / \mathrm{l}$ at T180 $(P=0.893)$.
\end{abstract}

Conclusion: Ninety minutes after its administration, co-trimoxazole induced a significant reduction of the early glycaemic response to oral glucose in parallel with a $27-0 \%$ increase in insulin secretory response. Co-trimoxazole induced within 120 min a more than 10-\% blood glucose reduction in 2/3 of participants. However none of the volunteers experienced hypoglycaemia.

Keywords: Co-trimoxazole, Glycaemia, Adults

\footnotetext{
* Correspondence: sobngwieugene@yahoo.fr

${ }^{1}$ Department of Internal Medicine and Specialties, Faculty of Medicine and

Biomedical Sciences, University of Yaoundé 1, Yaoundé, Cameroon

${ }^{3}$ National Obesity Centre, Diabetes and Metabolic Diseases Unit, Yaoundé

Central Hospital, Yaoundé, Cameroon

Full list of author information is available at the end of the article
}

(c) The Author(s). 2016 Open Access This article is distributed under the terms of the Creative Commons Attribution 4.0 International License (http://creativecommons.org/licenses/by/4.0/), which permits unrestricted use, distribution, and reproduction in any medium, provided you give appropriate credit to the original author(s) and the source, provide a link to the Creative Commons license, and indicate if changes were made. The Creative Commons Public Domain Dedication waiver (http://creativecommons.org/publicdomain/zero/1.0/) applies to the data made available in this article, unless otherwise stated. 


\section{Background}

The HIV/AIDS is a threatening condition affecting 31 million of persons in the world and which has been responsible for 39 million of deaths since the beginning of the pandemic (UNAIDS 2014). That condition leads to a lowering of the immunity causing a high susceptibility to infections. In HIV/AIDS patients the use of cotrimoxazole for the treatment and prevention of opportunistic infections is recommend and is associated with a significant reduction in morbidity and mortality $[1,2]$.

Despite the inescapable place of co-trimoxazole in the management of HIV/AIDS patients, its use is not risks free [3]. It is responsible for a wide range of side effects such as nausea, vomiting, allergic skin reactions and hypoglycaemia [3]. Hypoglycaemia is an uncommon complication of co-trimoxazole use, maybe for lack of monitoring but, cases of severe hypoglycaemia were reported in patients receiving high dose of co-trimoxazole for opportunistic infections $[4,5]$. Those hypoglycaemias were concomitant to an increase in insulin secretion what suggesting a sulfonylurea-like mechanism. Likewise a study highlighted the hypoglycaemic potential of cotrimoxazole in glipizide and glyburide users [6]. Whether co-trimoxazole at prophylactic dose would induce similar side effects is unknown. The aim of this study was to assess the acute glycaemic effects of co-trimoxazole at prophylactic dose in healthy adults.

\section{Methods}

\section{Setting and participants}

The study was conducted at the National Obesity Center, Yaounde Central Hospital. We enrolled 20 healthy adults, living in Yaounde (Cameroon) during the study period; with no contraindication to co-trimoxazole use and free of any medication for other purpose. Other selection criteria included fasting blood sugar of less than $7 \mathrm{mmol} / \mathrm{l}$; Alanine Aminotransferase (ALAT) of less than tree fold the normal; and a glomerular filtration rate superior to $60 \mathrm{ml} / \mathrm{min} / 1.73 \mathrm{~m}^{2}$ of body surface.

\section{Procedure}

Each participant underwent on two separated occasion a 75-g oral glucose tolerance test, with (test) and without (control) oral administration of co-trimoxazole, $60 \mathrm{~min}$ before the oral glucose load when indicated. The two OGTT were separated by a period of $48 \mathrm{~h}$ and each participant was his own witness. To minimise systematic errors, one half of the participants started with the test OGTT and the other half with the control OGTT. The starting order was determined randomly. The cotrimoxazole used was named BERLOCID, and were manufactured by the MENARINI group in Berlin, Germany. The tablets contained $960 \mathrm{mg}$ of cotrimoxazole. Blood glucose response was measured using a OneTouch Ultra2 glucose meter at baseline and 30, 60, 90, 120 and $180 \mathrm{~min}$ following the oral glucose load on the two occasions. The insulin response was also assessed by a measure of C-peptide level at baseline, 60 and $180 \mathrm{~min}$ after the oral glucose load on the two occasions. The c-peptide level was determined using the MercodiaUltrasensitive C-peptide ELISA (Mercodia AB, Sylveniusgatan 8A, SE-754 50 Uppsala, Sweden); based on the direct sandwich technique in which two monoclonal antibodies are directed against separate antigenic determinants on the $\mathrm{C}$-peptide molecule. This test has a detection limit of $2.5 \mathrm{pmol} / \mathrm{L}$ and provides less than $1.8 \%$ of cross reactions.

\section{Outcomes}

The primary clinical outcome was a variation in blood glucose response of more than $20 \%, 2 \mathrm{~h}$ after the oral administration of co-trimoxazole during the OGTT with co-trimoxazole comparatively to the blood glucose response during the OGTT without co-trimoxazole. The secondary outcomes considered were a variation of more than $10 \%$ of the blood glucose response, any time after the administration of co-trimoxazole and a variation of the insulin secretory response during the OGTT with co-trimoxazole comparatively to the OGTT without co-trimoxazole.

\section{Statistical analysis}

Data was coded, entered and analyzed using the Statistical Package for Social Science (SPSS) version 21.0 for Windows (IBM Corp. Released 2012. IBM SPSS Statistics for Windows, Version 21.0. Armonk, NY: IBM Corp.). We compared absolute value of blood glucose response and $\mathrm{C}$-peptide secretory response with the non-parametric Wilcoxon test. A $p$ value of less than 0.05 was considered statistically significant.

\section{Results}

\section{Characteristics of the study population}

We enrolled 20 volunteers aged 23.0 (SD 2.0), with mean BMI of 22.3 (SD 3.6) $\mathrm{kg} / \mathrm{m}^{2}$; mean fasting blood glucose of 4.89 (SD 0.33) $\mathrm{mmol} / \mathrm{l}$; mean alanine aminotransferase of 5.58 (SD 3.56) ui/l and a mean glomerular filtration rate of 110.5 (SD 32.8) (Table 1).

\section{Variations in the glycaemic response during the control versus the test OGTT}

During the control OGTT vs. the test OGTT, the glycaemia varied from 4.83 (SD 0.39) $\mathrm{mmol} / \mathrm{l}$ vs. 4.72 (SD 0.28) $\mathrm{mmol} /$ 1 at T0 $(P=0.667)$, to 8.00 (SD 1.11$) \mathrm{mmol} / \mathrm{l}$ vs. 7.44 (SD $0.78) \mathrm{mmol} / \mathrm{l}$ at T30 $(P=0.048), 8.00$ (SD 1.17$) \mathrm{mmol} / \mathrm{l}$ vs. 7.67 (SD 1.00) mmol/l at T60 $(P=0.121), 7.33(\mathrm{SD} 0.94)$ $\mathrm{mmol} / \mathrm{l}$ vs. $7.11(\mathrm{SD} 0.83) \mathrm{mmol} / \mathrm{l}$ at T90 $(P=0.205), 6.78$ $(\mathrm{SD} 1,00)$ vs. $6.67(\mathrm{SD} 1.00) \mathrm{mmol} / \mathrm{l}$ at T120 $(P=0.351)$ and 
Table 1 Baseline characteristics of the study population

\begin{tabular}{ll}
\hline Characteristics & Mean values $(\mathrm{SD})$ \\
\hline Age & $23(2)$ \\
Sex $(\mathrm{M} / \mathrm{F})$ & $(15 / 5)$ \\
Body mass index $\left(\mathrm{kg} / \mathrm{m}^{2}\right)$ & $22.3(3.6)$ \\
Systolic bloc pressure $(\mathrm{mmHg})$ & $118(11)$ \\
Diastolic blood pressure $(\mathrm{mmHg})$ & $75(10)$ \\
Fasting blood glucose $(\mathrm{mmol} / \mathrm{l})$ & $4.89(0.33)$ \\
Alanine aninotranferase $(\mathrm{IU} / \mathrm{l})$ & $5.58(3.56)$ \\
Glomerular filtration rate $\left(\mathrm{ml} / \mathrm{min} / 1.73 \mathrm{~m}^{2}\right)$ & $110.5(32.8)$ \\
\hline
\end{tabular}

$S D$ standard deviation

4.72 (SD 1.39) $\mathrm{mmol} / \mathrm{l}$ vs. 4.72 (SD 1.56) $\mathrm{mmol} / \mathrm{l}$ at T180 $(P=0.747)$ (Table 2$)$. The ratio of area under the glycaemia curve during the control and test investigation was $96.7 \%$, thus a 3.3 decreased glycaemic response $(p=0.062)$ (Fig. 1). A decrease of glycaemia by more than $10 \%$ occurred in $6 /$ 20 participants at T30, 7/20 participants at T60 and 1/20 participant at T30 and T60.

\section{Variations in the insulin secretory response during the control versus the test OGTT}

The C-peptide response during the control vs. the test investigation varied from 278.1 (SD 57.5) pmol/l vs. 242.8 (SD 42.5) $\mathrm{pmol} / \mathrm{l}$ at T0 $(P=0.138)$, to 1845.6 (SD 423.6) $\mathrm{pmol} / \mathrm{l}$ vs. $2340.6(\mathrm{SD} 701.3) \mathrm{pmol} / \mathrm{l}$ at T60 $(P=0.345)$ and 1049.8 (SD 503.1) pmol/l vs. 1041.63 (SD 824.21) pmol/l at T180 $(P=0.893)$ (Fig. 2).

\section{Rate of co-trimoxazole induced hypoglycaemia}

None of the participants experienced co-trimoxazole induced hypoglycaemia.

\section{Discussion}

The co-trimoxazole is an antibacterial sulfonamide unavoidable in the management of HIV/AIDS patients but, it sometimes induced severe and even protracted hypoglycaemia when used in high dose. Our study aimed

Table 2 Variations in the glycaemic response during the control versus the test OGTT

\begin{tabular}{lllll}
\hline \multicolumn{2}{l}{ Glycaemia during control OGTT } & \multicolumn{4}{l}{ Glycaemia during Test OGTT } \\
\hline Time (minutes) & Mean (SD) & Mean (SD) & Difference (\%) & $p$ value \\
T-60 & $4.89(0.33)$ & $4.94(0.28)$ & -1.14 & - \\
T0 & $4.83(0.39)$ & $4.72(0.28)$ & 2.30 & 0,667 \\
T30 & $8.00(1.11)$ & $7.44(0.78)$ & 6.94 & 0,048 \\
T60 & $8.00(1.17)$ & $7.67(1.00)$ & 4.17 & 0,121 \\
T90 & $7.33(0.94)$ & $7.11(0.83)$ & 3.03 & 0,205 \\
T120 & $6.78(1.00)$ & $6.67(1.00)$ & 1.64 & 0,351 \\
T180 & $4.72(1.39)$ & $4.72(1.56)$ & 0 & 0,747 \\
\hline
\end{tabular}

SD Standard deviation, Glycaemia are express in $\mathrm{mmol} / \mathrm{l}$ and mean are compared by the Wilcoxon test to investigate the acute effects of co-trimoxazole at prophylactic dose on glucose metabolism in healthy adults. We noted an acute reduction in the glycaemic response, with $70 \%$ of the participants experiencing a reduction of more than $10 \%$ in the glycaemic response during the test OGTT compared to the control OGTT, some of them $90 \mathrm{~min}$ and others $120 \mathrm{~min}$ after co-trimoxazole administration. This reduction in glycaemic response was concomitant to an increase in insulin secretory response by $27 \%$.

Strevel and al. reported cases of severe and protracted hypoglycaemia secondary to high doses of co-trimoxazole in patients with hypoglycaemia risk factors $[4,5]$. Those risk factors include chronic renal failure (93\%), malnutrition, and concomitant administration of propoxyphene. Nunnari and al. also reported cases of hypoglycaemia secondary to high dose of co-trimoxazole. On the other hand, Schelleman and al. highlighted co-trimoxazole induced hypoglycaemia when associated to glipizide or glyburide [6]. The absence of hypoglycaemia in our experimentation could be related to our procedure. First we used a low dose of co-trimoxazole; secondly we used a dynamic test (a 75 g OGTT) which had the advantage to further stimulate the insulin secretion but at the same time prevent hypoglycaemia. Furthermore, those hypoglycaemias occurred in patients with others co-morbidities [4] or taking hypoglycaemic drug $[4,6]$ compared to our study where volunteers had no co-morbidities and conserved mechanism of counter regulation, which prevent hypoglycaemia and which is probably responsible of the trend to normalization $120 \mathrm{~min}$ after co-trimoxazole administration. Indeed, in healthy person, the counter regulatory mechanism are not only activated to reverse hypoglycaemia but, also to prevent its occurrence. That could justify the absence of hypoglycaemia signs. This is correlated by the study of Natalie S. Schwartz and al. which showed that the glycemic thresholds for activation of glucose counter regulatory systems are higher than the threshold for symptoms [7]. Thereby it would be interesting to assess the hypoglycaemic potential of co-trimoxazole in patients with co-morbidities and altered counter regulating mechanism.

Plausible mechanisms by which hypoglycaemia might occur is the stimulation of insulin secretion as reported by Nunnari and al. and Strevel and al. [4, 5], suggesting a sulfonylurea-like mechanism. So co-trimoxazole would fixed itself on the SUR1 subunit of the beta-cell ATP-sensitive potassium channel leading to the closure of ATP-sensitive potassium channels, then to the depolarization of the cell membrane with the opening of voltage-gated calcium channels. This produces an influx of calcium that stimulates fusion of the docked insulincontaining vesicles with the cell membrane and secretion of insulin into the extracellular fluid by exocytosis. 


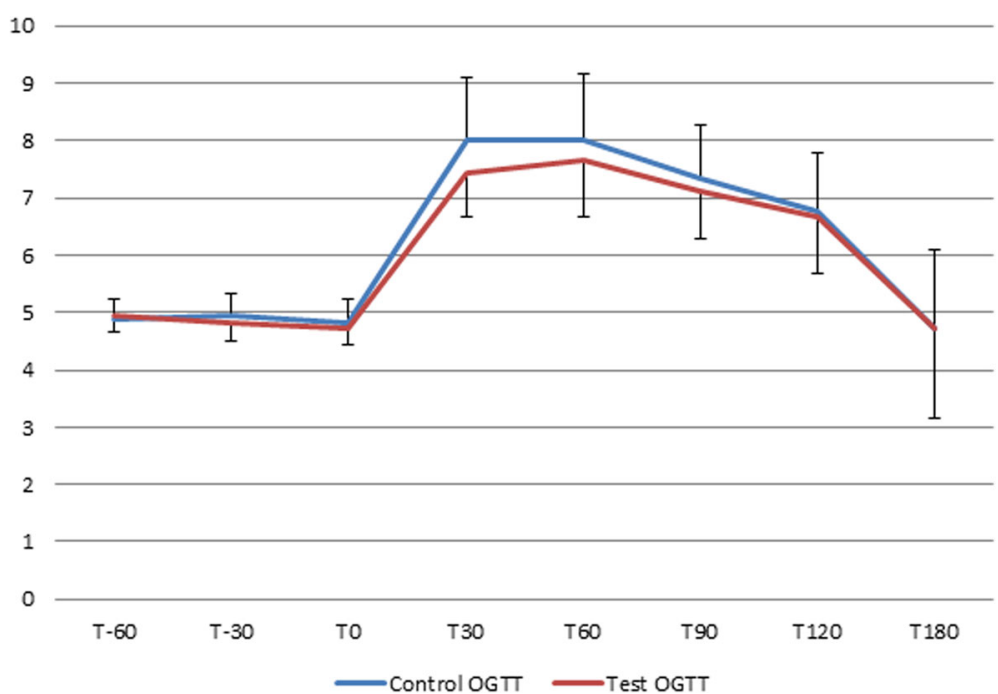

Fig. 1 Test versus control OGTT: Compared glycaemic response. Caption: $x$-axis: time in minutes, $y$-axis glycemia in mmol//

This is reinforced by the history of the discovery of sulfonylurea. Indeed, Marcel Janbon reported cases of reversible coma after glucose administration in patients treated with the antibacterial sulphonamide 2254 RP for typhoid fever. This finding aroused interrogations and this is how A. Loubatières highlighted the hypoglycaemic potential of 2254 RP.

This study shows that at prophylactic dose cotrimoxazole can be safely administered in healthy adult, and this is because of the activation of the counter regulatory system. Nevertheless a special attention should be paid when co-trimoxazole is administered at high dose like in the treatment of Pneumocystis jiroveci pneumonia, and to patients with comorbidities including renal insufficiency or malnutrition. Indeed malnutrition and kidney dysfunction are risks factors for severe hypoglycaemia in patients using high dose of co-trimoxazole as reported by Strevel and al. in a case series [4]. Moreover, Hemkisoy and al. and Arem and al. reported a case of co-trimoxazoleinduced hypoglycaemia in a malnourish patient and in another one with in chronic renal failure $[8,9]$. A monitoring of blood glucose level is advised in case of concomitant administration of co-trimoxazole and sulfonylureas, in order to rapidly detect and treat a potential hypoglycaemia due an excessive insulin secretion, especially in patients with relevant comorbidities.

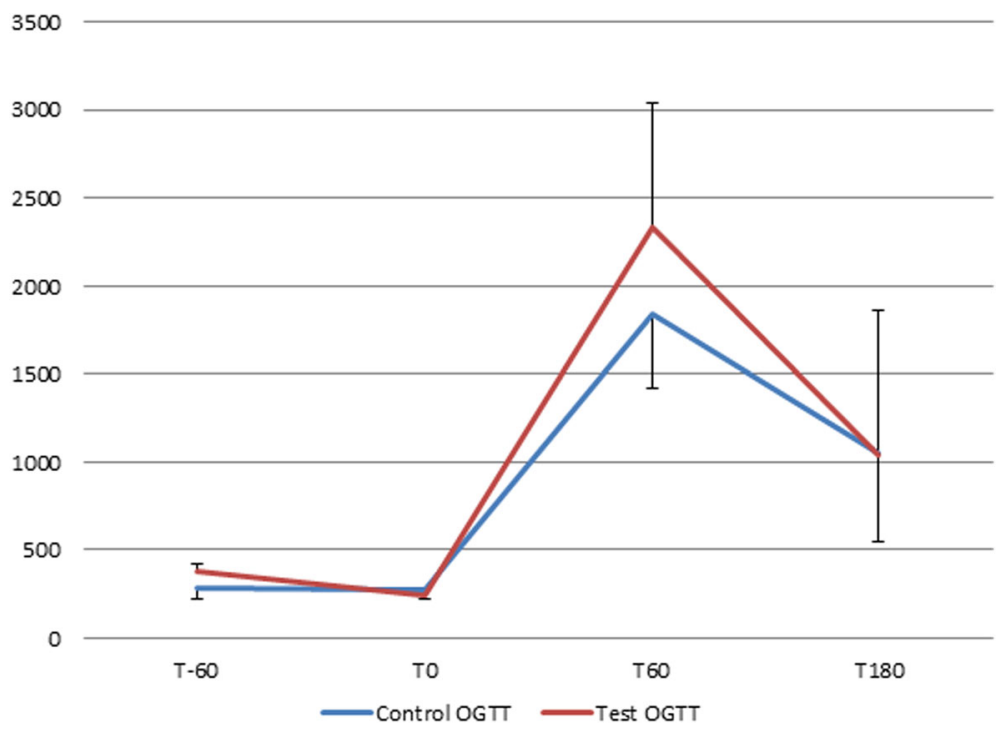

Fig. 2 Test versus control OGTT: compared C-peptide secretory response. Caption: $x$-axis: time in minutes, $y$-axis c-peptide in pmol/I 


\section{Conclusion}

Our study shows that $960 \mathrm{mg}$ of co-trimoxazole reduce the glycaemic response within 90 to $120 \mathrm{~min}$ after his administration but no hypoglycaemia was observed (probably related to the procedure). This reduction in glycaemic response was associated with an increase in insulin secretory response. Although ours finding cannot prove nor exclude a co-trimoxazole induced hypoglycaemia at prophylactic dose, we suggest to clinicians to be aware of a hypoglycaemic potential of co-trimoxazole and thus increase alertness, especially in patients receiving high dose, with comorbidities or polymedicated patients.

\section{Abbreviations \\ OGTT: 75-g oral glucose tolerance test; SD: Standard deviation}

\section{Acknowledgments}

To all the patients who participated to this study.

\section{Funding}

None.

\section{Availability of data and materials}

Data will be made available by the corresponding author upon request.

\section{Authors' contributions}

Study conception: ES, BK, MD. Data collection: BK, MCE. Laboratory analysis: BK, ES. Data analysis and Manuscript drafting: BK, JJNN, MAZ, ES. Critical revision of manuscript: JJNN, BK, MAK, MD, MCE, ES. All authors read and approved the final manuscript.

\begin{abstract}
Authors' information
BK, MCE, MAK: Faculty of Medicine and Biomedical Sciences, University of Yaoundé 1, Yaoundé, Cameroon; JJNN: Department of Medicine, Groote Schuur Hospital and University of Cape Town, Cape Town, South Africa; MD: National Obesity Centre, Diabetes and Metabolic Diseases Unit, Yaoundé Central Hospital, Yaoundé, Cameroon, ES: National Obesity Centre, Diabetes and Metabolic Diseases Unit, Yaoundé Central Hospital, Yaoundé, Cameroon and Department of Internal Medicine and Specialties, Faculty of Medicine and Biomedical Sciences, University of Yaoundé 1, Yaoundé, Cameroon.
\end{abstract}

\section{Competing interests}

The authors declare that they have no competing interests.

\section{Consent for publication}

All the authors approved the final version of the manuscript and consented for its publication.

\section{Ethical approval and consent to participate}

Before starting the study, an authorization was obtained from authorities of the Yaoundé Central Hospital and the Yaoundé University Teaching Hospital, and an ethical clearance was delivered by the Institutional Review Board of the Faculty of Medicine and Biomedical Sciences of the University of Yaoundé I, Cameroon. All the procedures used in the present study were in conformity with the current revision of the Helsinki Declaration. All participants were informed of the various aspects of the study, and they were enrolled only after providing a signed consent form.

\section{Author details}

${ }^{1}$ Department of Internal Medicine and Specialties, Faculty of Medicine and Biomedical Sciences, University of Yaoundé 1, Yaoundé, Cameroon. ${ }^{2}$ Department of Medicine, Groote Schuur Hospital and University of Cape Town, Cape Town, South Africa. ${ }^{3}$ National Obesity Centre, Diabetes and Metabolic Diseases Unit, Yaoundé Central Hospital, Yaoundé, Cameroon. ${ }^{4}$ Department of Physiological Sciences and Biochemistry, Faculty of Medicine and Biomedical Sciences, University of Yaoundé 1, Yaoundé, Cameroon. ${ }^{5}$ Biotechnology Centre, University of Yaoundé 1, Yaoundé, Cameroon.
${ }^{6}$ National Obesity Center, Yaoundé Central Hospital and Faculty of Medicine and Biomedical Sciences, University of Yaoundé 1, Yaoundé, Cameroon.

Received: 2 August 2016 Accepted: 25 October 2016

Published online: 15 November 2016

References

1. Cheng W, Wu Y, Wen Y, Ma Y, Zhao D, Dou Z, et al. Cotrimoxazole prophylaxis and antiretroviral therapy: an observational cohort study in China. Bull World Health Organ. 2015;93(3):152-60.

2. Mermin J, Lule J, Ekwaru JP, Malamba S, Downing R, Ransom R, et al. Effect of co-trimoxazole prophylaxis on morbidity, mortality, CD4-cell count, and viral load in HIV infection in rural Uganda. Lancet Lond Engl. 2004;364(9443): 1428-34.

3. Ho JM-W, Juurlink DN. Considerations when prescribing trimethoprimsulfamethoxazole. CMAJ. 2011;183(16):1851-8.

4. Strevel EL, Kuper A, Gold WL. Severe and protracted hypoglycaemia associated with co-trimoxazole use. Lancet Infect Dis. 2006;6(3):178-82.

5. Nunnari G, Celesia BM, Bellissimo F, Tosto S, La Rocca M, Giarratana F, et al. Trimethoprim-sulfamethoxazole-associated severe hypoglycaemia: a sulfonylurea-like effect. Eur Rev Med Pharmacol Sci. 2010;14(12):1015-8.

6. Schelleman $H$, Bilker WB, Brensinger CM, Wan F, Hennessy S. Anti-infectives and risk of severe hypoglycemia in glipizide and glyburide users. Clin Pharmacol Ther 2010;88(2):214-22

7. Schwartz NS, Clutter WE, Shah SD, Cryer PE. Glycemic thresholds for activation of glucose counterregulatory systems are higher than the threshold for symptoms. J Clin Invest. 1987;79(3):777-81.

8. Hekimsoy Z, Biberoǧlu S, Çömlekçi A, Tarhan O, Mermut C, Biberoǧlu K. Trimethoprim/sulfamethoxazole-induced hypoglycemia in a malnourished patient with severe infection. Eur J Endocrinol. 1997;136(3):304-6.

9. Arem R, Garber AJ, Field JB. Sulfonamide-induced hypoglycemia in chronic renal failure. Arch Intern Med. 1983;143(4):827-9.

Submit your next manuscript to BioMed Central and we will help you at every step:

- We accept pre-submission inquiries

- Our selector tool helps you to find the most relevant journal

- We provide round the clock customer support

- Convenient online submission

- Thorough peer review

- Inclusion in PubMed and all major indexing services

- Maximum visibility for your research

Submit your manuscript at www.biomedcentral.com/submit
Biomed Central 